\title{
The Fake, the Flimsy, and the Fallacious: Demarcating Arguments in Real Life
}

\section{Maarten Boudry, Fabio Paglieri \& Massimo Pigliucci}

\section{Argumentation}

An International Journal on Reasoning

ISSN 0920-427X

Argumentation

DOI 10.1007/s10503-015-9359-1

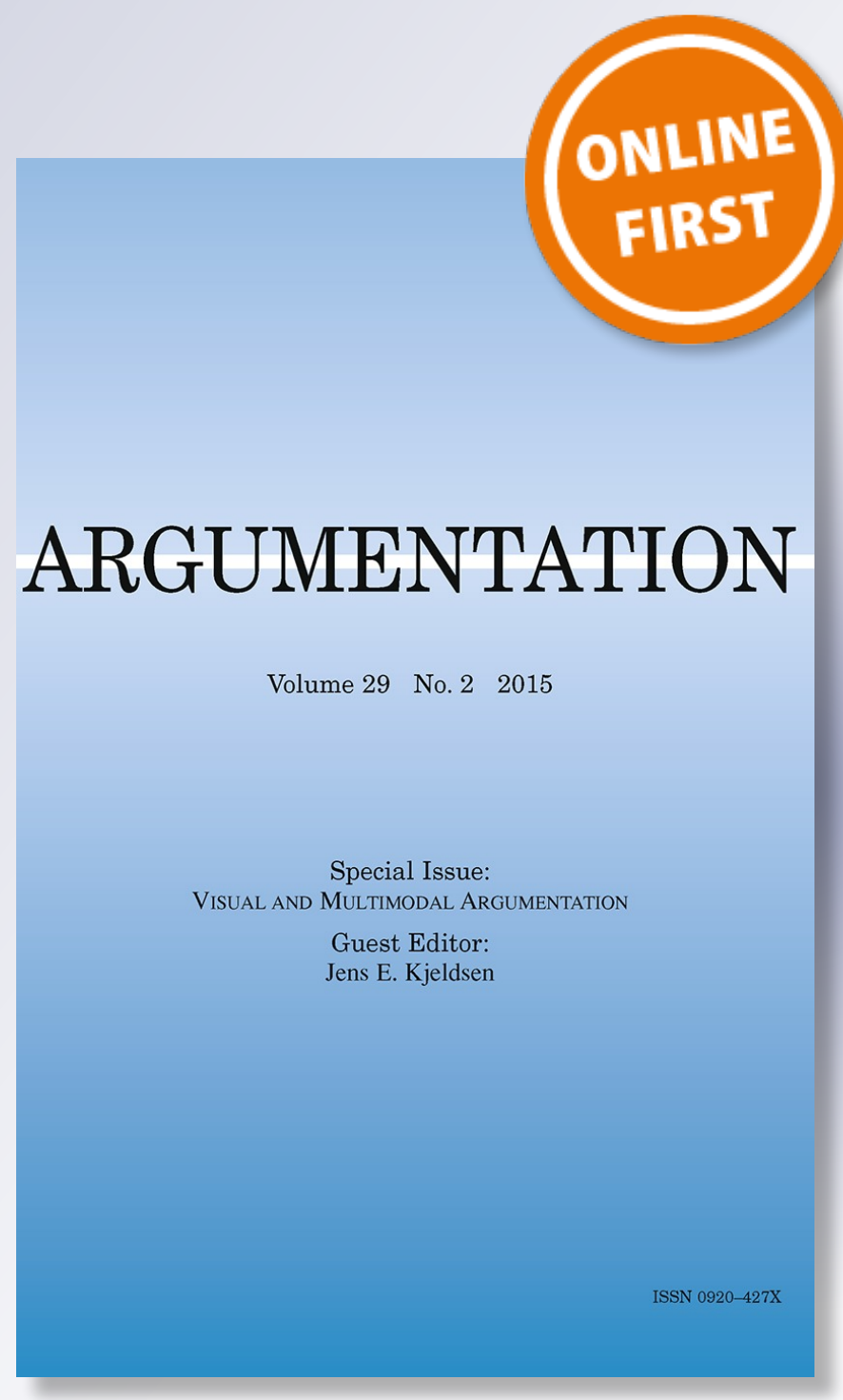

黛 Springer 


\title{
The Fake, the Flimsy, and the Fallacious: Demarcating Arguments in Real Life
}

\author{
Maarten Boudry ${ }^{1}$ Fabio Paglieri² ${ }^{2}$ \\ Massimo Pigliucci ${ }^{3}$
}

\begin{abstract}
Philosophers of science have given up on the quest for a silver bullet to put an end to all pseudoscience, as such a neat formal criterion to separate good science from its contenders has proven elusive. In the literature on critical thinking and in some philosophical quarters, however, this search for silver bullets lives on in the taxonomies of fallacies. The attractive idea is to have a handy list of abstract definitions or argumentation schemes, on the basis of which one can identify bad or invalid types of reasoning, abstracting away from the specific content and dialectical context. Such shortcuts for debunking arguments are tempting, but alas, the promise is hardly if ever fulfilled. Different strands of research on the pragmatics of argumentation, probabilistic reasoning and ecological rationality have shown that almost every known type of fallacy is a close neighbor to sound inferences or acceptable moves in a debate. Nonetheless, the kernel idea of a fallacy as an erroneous type of argument is still retained by most authors. We outline a destructive dilemma we refer to as the Fallacy Fork: on the one hand, if fallacies are construed as demonstrably invalid form of reasoning, then they have very limited applicability in real life (few actual instances). On the other hand, if our definitions of fallacies are
\end{abstract}

Maarten Boudry

maartenboudry@gmail.com

Fabio Paglieri

fabio.paglieri@istc.cnr.it

Massimo Pigliucci

massimo@platofootnote.org

1 Department of Philosophy and Moral Sciences, Ghent University, St.-Pietersnieuwstraat 49, 9000 Ghent, Belgium

2 Istituto di Scienze e Tecnologie della Cognizione, Consiglio Nazionale delle Ricerche, Rome, Italy

3 Department of Philosophy, City College of New York, 160 Convent Av, New York, NY 10031, USA 
sophisticated enough to capture real-life complexities, they can no longer be held up as an effective tool for discriminating good and bad forms of reasoning. As we bring our schematic "fallacies" in touch with reality, we seem to lose grip on normative questions. Even approaches that do not rely on argumentation schemes to identify fallacies (e.g., pragma-dialectics) fail to escape the Fallacy Fork, and run up against their own version of it.

Keywords Fallacies - Demarcation - Fallacy Fork · Pseudoscience - Argumentum ad ignorantiam - Genetic fallacy · Post hoc ergo propter hoc . Ad hominem . Ecological rationality · Probabilistic reasoning · Pragma-dialetics · Destructive dilemma $\cdot$ Irrationality

\section{Introduction}

Popular books and articles on pseudoscience and critical thinking often contain a section on informal fallacies (Sagan 1996; Shermer 1997; Carroll 2000; DiCarlo 2011; Van Bendegem 2013; Nieminen and Mustonen 2014), listing the standard examples that have been handed down since the times of Aristotle. It is remarkable, however, that reallife instances are noticeably absent from the very same textbooks. Despite the worthy goal of offering a "baloney detection kit", as Carl Sagan put it, arming the reader against nonsense and sloppy reasoning, the tools found in the kit rarely perform "serious logical duty" (Johnson 1987: 242). The diagnosis of this or that type of fallacy seems perfunctory, little more than an afterthought to the actual debunking, while accounts of fallacies are illustrated with toy examples that one is unlikely to encounter in real life. Fallacies, it seems, happen primarily in textbooks (Finocchiaro 1981).

Interestingly, although the standard view of fallacies as defective inferences is still predominant in the popular literature, argumentation theories have moved beyond it already several decades ago: ${ }^{1}$ starting from Hamblin's seminal work (1970), most modern approaches criticize the definition of a fallacy as logically invalid types of arguments. While each approach deals with the problem differently (for a comprehensive discussion, see van Eemeren 2001), they all share a shift towards pragmatics in the quest for a theory of fallacies. In fact, different theories can be ordered in terms of the respective weight given to formal versus pragmatic considerations. Does the pragmatic turn offer better tools for dealing with real life arguments, compared to the sterile standard treatment?

A limited pragmatic flavor can be found in the approach originally proposed by Woods and Walton (1982, 1989), and later abandoned by both: organize fallacies based on their degree of formal analyzability. More radical is the proposal articulated by Barth and Krabbe in their formal dialectics (1982), where fallacies are seen as argumentative moves that cannot be generated by a finite set of production rules for rational arguments. Even more emphasis on pragmatic considerations is found in the

\footnotetext{
1 Incidentally, this misalignment between popular textbooks and argumentation theories in the treatment of fallacies should raise a red flag for the latter: it implies either lack of relevance in the broader scholarly community, or a difficulty in providing effective tools for critical thinking education. Both are extremely undesirable states of affairs, which we should all strive to remedy.
} 
pragma-dialectic approach (van Eemeren and Grootendorst 1984, 1992, 2004), and Walton's pragmatic theory (for a mature exposition, see Walton 1995). The former sees fallacies as infringements of performance rules characteristic of a particular ideal type of argumentative engagement, known as critical discussion. The latter sees fallacies as illicit dialectical shifts across different dialogue types, in the sense that the attempted move is inappropriate with respect to its pragmatic context of application.

Although there is much more to each of the above approaches, what matters for our purposes is what they all have in common: a rejection of the traditional analysis of fallacies as logically invalid form of reasoning. This rejection implies that what is wrong with classical fallacy theory is an exclusive focus on inferential structure: enter pragmatics, and the problem is solved.

We beg to differ: while we certainly agree that a pragmatic-free fallacy theory is a non-starter, we also think that the roots of the problem lie deeper, affecting even pragmatic approaches. In this paper, we offer general reasons for the intractable nature of fallacies. First, we present what we termed the Fallacy Fork of argumentation theory, spelling out why cut-and-dry fallacies are unlikely to be found in real life conversations. Next, we apply the Fallacy Fork to some staple examples of fallacy theory (ad hominem and post hoc ergo propter hoc, genetic fallacy and ad ignorantiam). We then discuss whether pragma-dialectical approaches escape the Fallacy Fork, and offer some general psychological and rhetorical reasons for why the Fallacy Fork is here to stay. Finally, we conclude by sketching a more modest role for fallacies in the pragmatics of everyday argumentation, one that we see as more consistent with current advancements in argumentation theory and the psychology of reasoning.

Where possible, we draw on examples from real-life debates on pseudoscience and other irrational belief systems. Being prime examples of bad epistemic practices, pseudosciences provide an ideal testing ground for our theories about good and fallacious forms of reasoning. This approach takes inspiration from Gardner's (1957) early forays into the hinterlands of science. Full-blown fallacies, if they exist in real life, are most likely to be found in the domain of pseudoscience, and this is also where they may very well be consequential to our life. Pseudosciences are far from harmless, and can have serious effects on society and human health (Pigliucci and Boudry 2013a, b). If the theory of fallacies does not arm us against such real-life follies and their tangible consequences, this should be a cause for concern. Apart from those reasons for focusing on pseudoscience, we also want to draw analogies with the classical demarcation problem in philosophy of science. Philosophers of science have struggled with the question of epistemic demarcation at the level of wholesale belief systems and their methodologies. Fallacy theorists, for their part, have tried to identify bad epistemic practices at the level of individual arguments and inferences. As we shall see, there are interesting analogies, but also disanalogies, between the two categorization problems.

\section{Demarcation and the Fallacy Fork}

How to discriminate between sound and fallacious forms of reasoning? This is a problem of demarcation akin to the one between science and pseudoscience, which has kept philosophers of science busy ever since Popper proposed his falsifiability 
criterion as a way of demarcating genuine science. In both cases, the initial attraction of pursuing such a demarcation project is to find some shortcut for dismissing bad theories or arguments, sparing us the effort of analyzing each and every specimen. Philosophers of science have given up on this silver bullet approach to demarcation (Pigliucci and Boudry 2013b). In argumentation theory, too, identifying fallacies has turned out to be more complicated that initially hoped for. Research in the pragmatics of argumentation, reasoning heuristics and ecological rationality has shown that almost every known type of fallacy (both formal and informal) is closely related to forms of reasoning that are acceptable moves in a debate (Hahn and Oaksford 2006, 2007; Hansen and Pinto 1995; Walton 1992, 1995, 2010b; Yap 2012). In spite of this increased sophistication, the quest for silver bullets still seems to be part and parcel of the taxonomies of fallacies. For one thing, the very labels we attach to different fallacies (ad hominem, ad ignorantiam, post hoc ergo proper hoc, ad verecundiam, etc.) intimate that a single feature- the one it wears on its sleeve-is the distinguishing mark that damns the whole argument, regardless of the circumstances. Even when far more nuanced accounts of these fallacies are provided, it is still assumed that, once all relevant factors have been considered and weighted, a clear distinction can be drawn between genuine fallacies and their harmless counterparts-an assumption recently challenged by Woods (2013).

For a long time, this was due to a deep seated affection for the traditional, Aristotelian view of fallacies. In 1987, Johnson claimed that fallacy theorists who were critical of the standard treatment still clung to the "historical nucleus of the idea of a fallacy as a logically bad argument" (Johnson 1987: 245). While this may be less true today, the belief that it is useful to talk about such a thing as a "fallacy" still stands, now colored by an increased awareness of the pragmatics of argumentation. $^{2}$

Philosophers of science, too, have clung to the notion of "pseudoscience", even though they have abandoned simple solutions to the demarcation problem. However, an important difference arises here: while both demarcation problems resist a neat solution in terms of necessary and sufficient conditions, the term pseudoscience is at least descriptively valid, in that it groups together a wide variety of real-life belief systems (astrology, homeopathy, creationism, etc.) that share a lot in common: while they all pretend to be science, none of them comes even close to the epistemic rigor of genuine science, and all of them suffer from similar flaws (Pigliucci and Boudry 2013b; Boudry and Braeckman 2011). In the case of fallacies, however, it turns out that, the closer we zoom in on the phenomenon, the more it seems to vanish (examples are provided below). Pragmatic considerations, as we shall see, cannot save the day-on the contrary, they are actually part of the problem.

As a challenge to the conceptual kernel of fallacy theory (i.e., the idea of identifiable types of erroneous reasoning), we spell out a destructive dilemma called

\footnotetext{
${ }^{2}$ Moreover, the recourse to a more or less traditional list of fallacies (what Woods 2013 aptly named "the gang of eighteen") is still very much in fashion, even in those textbooks that explicitly insist on the importance of the dialogical context in assessing fallacies, as in Tindale's Fallacies and Argument Appraisal (2007; on this point, see Krabbe 2009).
} 
the Fallacy Fork. Take the definition of any fallacy in the standard list. If we construe the argumentation scheme exemplifying this fallacy as a non-defeasible and deductive inference (or even just a strong inductive argument), it will be easy to show that it is clearly invalid (or inductively very weak). So far so good. The problem is that one hardly ever encounters "fallacies" in this guise. They only appear as highly artificial textbook cases, designed to be knocked down easily (Finocchiaro 1981). ${ }^{3}$ That is the first horn of the Fallacy Fork. If we want to bring our argumentation scheme in touch with reality, we should make it less stringent, watering it down to a defeasible mode of inference and specifying the pragmatic conditions for its (in)felicitous application. Although we will now find plenty of instances in real life, the strength of the arguments instantiating the scheme will depend on a host of contextual factors that are not captured by the scheme itself. Our "fallacy" has lost its bite. This is the second horn of the dilemma. We will now put a number of fallacies before the Fallacy Fork and see how they fare.

\subsection{Post Hoc Ergo Propter Hoc}

According to the standard view, the fallacy of post hoc ergo propter hoc is committed whenever one infers that, if B occurred after A, it follows that A causes B. In the words of one logic textbook, it is the "error of concluding that an event is caused by another simply because it follows from that other" (Copi and Cohen 1998). For example, I am taking a homeopathic pill against my cold, and 3 days later I feel better. I conclude that homeopathy works. Psychologists have found this form of inference to be pervasive in human judgment (Kahneman et al. 1982). But is this diagnosis as straightforward as it seems? Woods and Walton (1977) have developed a theoretically unified account of post hoc reasoning, but have later abandoned this approach, admitting that no general account of post hoc fallacies is in the offing.

Remember the Fallacy Fork introduced above: if the argument is construed as a non-defeasible and deductive inference (or even just a strongly inductive argument), it is clearly invalid. In the case of the homeopathic pill, the critical thinker will point out that there are many different things that could have caused me to feel better. To infer that the pills cured me, merely because my taking them preceded the cure, is an unwarranted leap.

The problem is that one hardly ever encounters the argument in this guise. Most lay people are aware of the possibility of sheer coincidence, and would not take the mere succession of two events as sufficient grounds for establishing a causal link. Even die-hard homeopaths would not argue that the efficacy of the pill deductively follows from observing one such sequence of events, setting aside any other consideration. To bring the fallacy scheme in touch with real life, we could therefore relax it into an abductive form of inference: "if B occurred after A, it is plausible (though not certain) to infer that A caused B". Now we indeed find plenty

\footnotetext{
3 This is probably a side-effect of a more general problem with argumentation textbooks, namely, their tendency to rely on artificial and simplified pseudo-examples of arguments, be they allegedly valid or not (on the implications of this practice for fallacy theory, see Walton 1989).
} 
of instances of this form of reasoning in real life. Whether or not such inferences are reasonable, however, depends on the specific context. First, people typically rely on causal background knowledge when making such a causal inference, even if such premises are left implicit. Few people will take the mere succession of two events as sufficient for making a causal inference. To make the argument more realistic, we should therefore add the proviso "given that there is a plausible causal mechanism linking A and B". Furthermore, we should take into account the prior probability of the consequent, the level of inductive support that is claimed, and the prudential burden of proof (Pigliucci and Boudry 2013a).

Take the relevance of priors. It matters a great deal how likely B was to happen anyway, without the occurrence of $\mathrm{A}$. If $\mathrm{B}$ is an exceptional event (cure from a lethal disease) it is reasonable to suspect that some noticeable event occurring before B may have been the cause, or a major cause (Pinto 1995). ${ }^{4}$ If the patient was trying out an unorthodox therapy, for example, his case is definitely intriguing, worth pursuing in more detail. It is quite possible that we will find no further evidence for a causal link between A and B, but this is irrelevant. The only thing we need to establish at this point is that the plausibility of the causal inference depends on the prior probability of the effect, which is not captured in the formal structure of the post hoc ergo propter hoc fallacy. This is a basic principle that even believers in pseudoscience intuitively understand. Nobody would credit her homeopathic medicine, or her lucky socks, for the sun rising the next day, even though the two events do follow one another. Religious believers rarely credit the gods for events that were bound to happen anyway, as a result of natural processes (Boudry and De Smedt 2011). The mere succession of two events, without other probabilistic reasons and a causal background story, rarely provokes a propter hoc inference. As Pinto pointed out: "Post hoc reasoning takes place against a backdrop of experience, knowledge, and perceptual expectation that shapes its direction and renders it at least minimally rational. But then post hoc reasoning never is concluding that one event is caused by another simply because it follows the other." (Pinto 1995: 308)

Next, the plausibility of a causal mechanism linking A and B strengthens or weakens the causal inference. In the example of the homeopathic pill, this is what clinches the case for skeptics (apart from lack of empirical evidence). Barring some revolution in chemistry, water has no memory, and homeopathic dilutions cannot possibly have the claimed effect. But compare that with another example. A few hours after eating some tasty mushroom, I feel sick. I conclude that the mushroom must have been poisonous. Formally, this is an example of post hoc ergo propter hoc, in its defeasible variant. Given that food in general and mushrooms in particular may contain toxins, which in turn are known to induce nausea, however, it seems quite sensible to blame the mushroom, pending further investigation. Again, the prior probability of the effect will also be relevant. If I am seated in an airplane that has just taken off, and I know that I am susceptible to airsickness, the mushroom is less likely to be the culprit. Finally, from a prudential point of view, it

\footnotetext{
${ }^{4}$ As the web comic xkcd once put it: "Correlation doesn't imply causation, but it does waggle its eyebrows suggestively and gesture furtively while mouthing 'look over there'."
} 
could well be rational to assume a causal connection and to avoid that type of mushroom altogether, even on relatively flimsy grounds (e.g., an unlikely causal story, or based on a single occurrence). Would you risk taking a bite of another mushroom? (Galperin and Haselton 2012) Or would you forgo a new and experimental therapy, based on tantalizing anecdotal evidence, if you have no other alternatives $?^{5}$ Most of these principles of probabilistic reasoning are intuitively applied in real life, even if rarely made explicit. However, they are not captured in the argumentation structure of the fallacy.

Of course, fallacy theorists can specify the fulfillment of such conditions in the argumentation scheme of the fallacy, but then it seems to lose much of its bite. Walton, for example, after discussing the post hoc fallacy, ends up with the somewhat lame conclusion that "the error would seem to be one of leaping too quickly to such a conclusion, without taking other factors into account that might defeat the inference" (Walton 1995: 57). Fair enough, but this leaves almost all the work to be done. What we are left with at this point is a misleading label suggesting a fundamental logical flaw that really isn't there. In particular, the label suggests a dichotomy between valid causal inferences and fallacious ones. By doing so, it encourages a simplistic construal of real-life arguments, exaggerating their intended force and ignoring their probabilistic and pragmatic context. ${ }^{6}$ There is nothing wrong or fallacious with post hoc reasoning per se. Indeed, witnessing the succession and contiguity of two events may be our primary way of acquiring causal knowledge.

\subsection{Ad Hominem}

Most educated people know about the ad hominem fallacy. It is probably one of the fallacy labels that is most often thrown around in popular discourse, in political debate, and especially on Internet forums. But is a person's character or personal background always strictly irrelevant to the credibility of her arguments, as fallacy theory stipulates? There is no formal way to distinguish legitimate suspicions about someone's personal background and ad hominem slander (Brinton 1995). In many contexts, the plausibility of an argument depends on the credentials, personal background and past actions of the speaker (Macagno 2013). The Fallacy Fork presents itself again. Construed as a deductive inference, ad hominem reasoning is invalid. But few reasoners would maintain that the falsehood of a claim follows inexorably from the bad character of the claimant. And indeed, deductive versions of the ad hominem inference are hard to find in real life. Take a toy example: " $\mathrm{X}$ is a member of the CATO institute, therefore it follows that his case against climate

\footnotetext{
5 Perhaps you would, if you are worried about other harmful side-effects. Given that hardly any active substance is free of side-effects, your decision would be reasonable. In medicine, it's difficult to make an omelet without breaking some eggs.

${ }^{6}$ Lest some readers take us as pessimists of the worst kind, this is a passage from the concluding chapter of John Woods' recent lengthy monograph on fallacies: "Most of the work in the logic of reasoning has yet to be done. Most of what needs doing has yet to be formulated, let alone achieved" (2013: 521). Notice that here Woods refers to the treatment of fallacies in general, not just the few examples covered in this paper.
} 
change is rubbish". This argument as it stand is invalid. Not surprisingly, few would make it. But does that mean that membership of a libertarian, free-market promoting think tank is completely irrelevant when it comes to assessing someone's arguments against climate change?

In a court case, it is perfectly reasonable to level a direct ad hominem charge against a witness, casting doubt on his trustworthiness. It is certainly acceptable to point out some shared interest with the defendant, by doing which one can undermine the credibility of the witness' statements. Such a move is admissible because, as an empirical generalization, people who have a shared interest with the defendant (or, conversely, who have an axe to grind with him) can be expected to be biased in their judgment. To accuse a lawyer of committing the ad hominem fallacy in this context is to miss the point, because one usually does not imply that the witness must be lying, nor even that it is highly plausible that he is. Although even an inveterate communist can make some valid points in Stalin's defense, we are rightly suspicious about his apology, at least in the absence of any hard evidence to back up his claims.

Some writers have argued that ad hominem arguments are admissible as long as they are directed at someone's advocacy of $\mathrm{P}$, while they are fallacious when targeting $\mathrm{P}$ itself (Brinton 1995). As a logical point, this principle is unassailable, but again, it is not very helpful in real life. Many arguments have a partly testimonial character, and stand or fall with the credentials of the person advocating them. In an uncertain world, with limited access to the relevant data, we often have to put some trust in the good faith of the claimant, and this remains true (or even becomes more so) in a world where most data is accessed indirectly, e.g., online (on the relationship between trust, argumentation and technology, see Paglieri 2014). In his classic The Demon-Haunted World, Carl Sagan, perhaps in the spirit of openmindedness, chooses the following example of an ad hominem fallacy directed against a creationist: "The Reverend Dr. Smith is a known Biblical fundamentalist, so her objections to evolution need not be taken seriously" (Sagan 1996: 212). But even Sagan's imaginary example, bending over backwards to the other side, exposes the uselessness of the ad hominem label. Of course the fact that Dr. Smith is a known Biblical fundamentalist, and hence committed to the literal word of the Genesis myth, undermines her credibility as a critic of evolution. To be sure, even a Biblical fundamentalist can mount a convincing case against some aspect of evolutionary theory, once in a while. But then again, that is mostly not what is at stake when people raise ad hominem charges.

Even in science, where researchers take pains to eliminate the subjective elements from their work, for example by making all their data publicly available and describing the exact procedures being followed, we still have to take their word that no data was omitted or manipulated, that the described protocol was duly followed, etc. Hence, it is reasonable to be suspicious of medical researchers who are on the payroll of pharmaceutical companies, particularly those who try to cover up such connections. To raise the ad hominem flag in this situation would be inappropriate, even though the argument formally exemplifies the template of $a d$ hominem reasoning (Yap 2012; Walton 2010a).

Consider the example of a child who rejects her mother's admonition against smoking because she herself smokes a pack a day (Walton 2010a). Is the child 
guilty of ad hominem reasoning? After all, she tries to undermine the case against smoking by pointing out facts about the claimant's personal life, accusing her mother of hypocrisy. But this analysis distracts from the possible validity of cues about someone's background. The child is not dumb: if the arguments against smoking are so decisive, why has the parent not given up smoking herself? You would expect some consistency if the parent was being truthful. Does the parent have ulterior motives perhaps? A host of complications now arise. The parent may explain about the addictive nature of nicotine and about weakness of will, and relate her own fruitless attempts to give up smoking. Still, the child may remain skeptical of someone who does not practice what she preaches. By this point, however, distinctions between valid and fallacious forms of reasoning are no longer captured by the standard formulas. Only someone who believes that smoking must be safe, since those who warn against it are hypocrites, would be committing a clear-cut fallacy. But who would be as obtuse as to make such a far-reaching claim? In the end, argumentation theorists have been forced to come up with unwieldy schemes for the (acceptable) circumstantial ad hominem attack, such as this one:

Generalization: given that a advocates argument $\alpha$, which has proposition $\mathrm{A}$ as its conclusion, and a is personally committed to the opposite (negation) of A, as shown by commitments expressed in her/his personal actions or personal circumstances expressing such commitments, and a's credibility as a sincere person who believes in his own argument has been put into question, then generally, but subject to qualifications in special circumstances, the plausibility of a's argument $\alpha$ is decreased. (Walton 2010a: 12)

There is an interesting connection with the traditional demarcation problem in philosophy of science (Pigliucci and Boudry 2013b). In debates about pseudoscience, questions concerning the character of pseudoscientists often arise. Pseudoscientists are accused of evasive behavior, willful obscurantism, using rhetorical ploys, selective use of evidence, or even manipulating data. In many cases, such suspicions are justified and relevant to the issue at hand. Philosophical purists, however, have argued that the merits of a theory should not be conflated with the personal flaws of its advocates. For example, Laudan (1982: 17) has claimed that, if we think that the status of a theory is affected by the dogmatic behavior of its adherents, we are staging an "ad hominem" attack because we are "egregiously confus[ing] doctrines with the proponents of those doctrines" (see also Grünbaum 1979). But this will not fly. Generally speaking, doctrines stand or fall by the evidence and arguments adduced by those advocates. ${ }^{7}$ For example, when psychologist Daryl Bem presented his data allegedly demonstrating the existence of psi, many skeptics were suspicious of his results, even before they had taken a close look, because of Bem's avowed sympathy for the paranormal. This

\footnotetext{
7 Indeed, when there is no canonical version of a doctrine, with clear definitions of its central concepts and propositions, we only have the behavior of its defenders to go by (Boudry and Braeckman 2011). For example, in the face of negative findings, some parapsychologists have argued that psi is an actively evasive force, manifesting itself only when there are no dissenters around (Kennedy 2003). Some have even speculated that skeptics may emit countervailing catapsi canceling out the original effect. What should we make of such moves?
} 
suspicion was borne out by subsequent failures to replicate the results (Wagenmakers et al. 2011; Alcock 2011), and the discovery of major flaws in his protocol and statistical procedures (Ritchie et al. 2012). This is not to say that Bem was cheating, although he may well have been. Subtle methodological errors or sloppy controls may be sufficient to account for Bem's spurious results. The upshot of this story, however, is that concerns about the arguer's character motivated suspicion and further inquiry, which turned out to be absolutely warranted.

Real arguments are made in an uncertain world, where information is scarce and incomplete, and there is plenty of circumstantial but almost no conclusive evidence (Gigerenzer 2008). Traditional argumentation schemes, however, as Cummings (2002: 121) pointed out, follow a linear progression from established premises to conclusion, with a hierarchy of (un)certainty:

An inquiry that assumes a hierarchical structure, in which reasoning proceeds linearly from propositions that are well known to propositions that are less well known, is ill-equipped to accommodate the reasoning strategies that occur in contexts of knowledge deprivation and epistemic uncertainty.

As applied to ad hominem reasoning: arguments may not bear the sins of their originators, but when the latter are questionable characters, the former do call for closer scrutiny.

\subsection{Argumentum Ad Ignorantiam}

Does absence of evidence constitute evidence of absence, as the dictum goes? The portentous label argumentum ad ignorantiam suggests that it doesn't. But it is not difficult to come up with an acceptable instance of an argument from ignorance. ${ }^{8}$ For instance, a skeptic argues that a wave of recovered memories about satanic abuses is likely the product of fabrication or suggestive therapeutic techniques, because we have never found any material traces of these satanic cults and their ominous gatherings. Let's compare this to the oft-heard creationist argument from ignorance about the (alleged) gaps in the fossil record. If evolution happened, where have all the intermediate forms gone?

The two arguments are formally equivalent, and if construed as deductive inferences, both are obviously invalid (cf. the Fallacy Fork). Taken as inductive arguments, however, their strength hinges on tacit probabilistic assumptions that are not captured in the formal structure of the ad ignorantiam fallacy (Hahn and Oaksford 2006, 2007). ${ }^{9}$ The determining factor, in Bayesian terms, is the likelihood $\mathrm{P}(\mathrm{ElH})$ of the probability of observing the missing evidence on the assumption that

\footnotetext{
${ }^{8}$ Remember that any negative claim can be translated into a positive one: any existential claim can be translated into a negative universal, and vice versa $(\exists x A x$ is logically equivalent to $\sim \forall x \sim A x$, and $\sim \exists \mathrm{xAx}$ is logically equivalent to $\forall \mathrm{x} \sim \mathrm{Ax})$.

9 While preparing this paper for publication, we discovered the excellent work by Hahn and Oaksford (2006, 2007) bearing out many of these points on the probabilistic factors underlying the varying strengths of so-called fallacies. With regard to the ad ignorantiam fallacy, Hahn and Oaksford develop a rigorous Bayesian framework accounting for the various types of negative argumentation, and the conditions under which they are acceptable (see also our earlier Pigliucci and Boudry 2013a).
} 
the hypothesis is true. Walton spells this out in terms of a search through a knowledge base: "there has been a search through the knowledge base that would contain A that has been deep enough so that if A were there, it would be found." (Walton 2010b: 177)

In the case of the satanic cults, this likelihood is very high. Typical recovered recollections about satanic abuse involve the ritual slaughtering and eating of babies. Where did those newborns come from? If such satanic sacrifices really happened, surely some infant bodies would have turned up by now, or there would have been cases of missing babies (this is absence of evidence). Similar considerations apply to the idea of alien abductions, another favorite fantasy of memory therapists (Mack 1995; Jacobs 1998). Surely a spacecraft hovering above cities and beaming up innocent citizens would have been (occasionally) captured on high-quality footage by now. All we have, however, is a handful of blurry photographs, reports of strange lights in the night sky, and lots of abductions stories. ${ }^{10}$

In the case of the fossil record, however, the likelihood of finding the missing fossils is demonstrably low with respect to evolutionary theory, because of the rarefied conditions that lead to fossilization. Before making a convincing argumentum ad ignorantiam, it behooves the creationist to show that the likelihood of digging up intermediate fossils for any pair of lineages, conditioned on the truth of evolution, is much higher than scientists admit. But the fact that the creationist is arguing from lack of knowledge does not invalidate his case as such. Scientists do it all the time.

In principle, appeals to absence of evidence can also be made to establish a positive claim. A notorious instance is that of senator McCarthy accusing American citizens of communist sympathies on the grounds that "there is nothing in the files to disprove Communist connections" (quoted in Walton 1999: 167). The charge seems gratuitous, because our intuition (and sense of fairness) tells us that the burden of proof falls on McCarthy to provide evidence for Communist sympathies, not on the accused to disprove such allegations, which may be very difficult to do (Pigliucci and Boudry 2013a). But even this sort of case is more complicated than it seems at first blush. The crux seems to be how large the threat of communism was for American society at the time, and how likely disproof of communist sympathies would turn up after investigation, conditioned on the hypothesis that the suspect had no communist ties (from a prudential point of view, we should also take into account the moral value of the presumption of innocence). Sometimes the failure to disprove a hypothesis provides good presumptive grounds for accepting it. For example, a biologist may assume that a newly discovered bird is oviparous (i.e., lays eggs), on the grounds that nobody has proven the opposite. As in the case of the other presumed fallacies, then, it is impossible to distinguish between legitimate and fallacious arguments ad ignorantiam on formal grounds. Differences arise from a host of contextual factors, such as background knowledge, prudential reasons and

\footnotetext{
${ }^{10}$ Ufologists typically resort to invoking large-scale cover-ups-involving various governments, the Illuminati, the aliens themselves, or all of them together-to explain away this dearth of evidence, but such explanations are, of course, blatantly ad hoc (Boudry and Braeckman 2011).
} 
relevant likelihoods, which can be quantified in a Bayesian framework, but are unlikely to determine a clear-cut verdict of fallaciousness in real-life cases, where all the key contextual factors are uncertain and/or subject to further debate.

\subsection{Genetic Fallacy}

To commit the genetic fallacy, according to the received view, is to discredit some point of view, theory or experience on the basis of its origins, or the character of its originator. ${ }^{11}$ Some instances are closely related to the ad hominem fallacy (if indeed it is a fallacy). This mode of reasoning is fallacious, according to the traditional view, because the historical roots of an entity $\mathrm{X}$ should never have any bearing on our (epistemic, moral, aesthetic) evaluation of $\mathrm{X}$. The experience of love is not debased because it is the result of brain chemistry, and religion is not an illusion just because it arose as a by-product of evolutionary forces. To think otherwise, as William James wrote in The Varieties of Religious Experience, is to believe that "the same breath which should succeed in explaining their origin would simultaneously explain away their significance" (James 2008: 16-17). Other alleged instances of the genetic fallacy dismiss ideas because of their historical roots: for example, a ban on smoking in public spaces is rejected because Nazi Germany was the first to implement it; an argument in defense of free markets is dismissed because it was advanced by a libertarian think tank (see above).

Again, we are faced with the Fallacy Fork. If the genetic fallacy takes the form of a deductive mode of inference, it is obviously invalid. In Joseph Heller's Catch 22, Yossarian rightly remarks: “Just because you're paranoid doesn't mean they aren't after you". Indeed, some persons suffering from clinical paranoia are really being persecuted (and have good reasons to think so). But, again, how many of such deductive fallacies do we encounter in real life? Aren't things usually a bit more complicated?

Oftentimes, when someone casts doubt on the origins of some $\mathrm{X}$, as a way of undermining our confidence in $\mathrm{X}$, this is brought forward as a relevant consideration bearing upon its status, not as a knock-down argument. And this is eminently reasonable. Yes, paranoid people can turn out to be really shadowed by the CIA, but for solid probabilistic reasons, we don't take their say-so at face value.

In the absence of robust and independent evidence for $\mathrm{p}$, shedding light on the origins of p really can undermine (or undergird) p's epistemic status. In many cases, the so-called genetic fallacy is actually an inference to the best explanation, based on limited information. This point is relevant to recent debates about the origins of religion. Atheists have argued that recent cognitive and evolutionary explanations of religion undermine its truth claims (Kahane 2010). ${ }^{12}$ In response, theists have hurled

\footnotetext{
11 The fallacy is sometimes spelled out as the conflation of context of discovery and context of justification (Salmon 1984; Ward 2010).

12 In a recent paper, Jong and Visala (2014) argue that the evolutionary account of religion is irrelevant to the latter's epistemic status: either we have independent grounds for belief in God's existence, or we do not have any such grounds. In the former case, the genealogy of religion does not affect our evidence for God, and in the latter case, we should just point out that belief in God is unjustified, which is sufficient to undermine it. In a perfect world, the point is unassailable. If we really have a conclusive proof for God's
} 
the charge of "genetic fallacy" back at them (e.g., Hart 2013), insisting that the origins of religious cognition are strictly irrelevant to its truth claims. This is a good example where the label "fallacy" has befuddled philosophical discussions. On careful examination, it is clear that a cognitive account of belief in supernatural agency does have a bearing on religious truth claims, even though no skeptic makes (or should make, at any rate) a simple deductive inference (Bering 2012).

Natural explanations of religious belief and experience (deriving from cognitive psychology and neurology) compete with supernatural accounts of the same phenomena put forward by theists. Did God instill these beliefs and experiences in us? (cf. Calvin's doctrine of the sensus divinitatis). Are they glimpses of some realm beyond the natural world? Or, alternatively, are they the outcome of mundane cognitive processes, in turn resulting from the adaptive make-up of our minds? If we succeed in explaining such phenomena-religious conversions, mystic experiences, a sense of supernatural presence-without invoking any supernatural entities, then the plausibility of any supernatural account of such experiences is thereby diminished. As it happened, in none of the cognitive-evolutionary accounts of religion that are currently in the running does the truth value of religious claims play any role whatsoever (Barrett 2007). The gradual emergence of the phenomena that we label as "religion" is perfectly understandable even if no Gods exist (indeed, they are better understandable on the supposition of atheism and the causal closure of nature: Boudry and De Smedt 2011). As Kim Sterelny rightly points out, in a review of the literature: "For the so-called 'genetic fallacy' (the erroneous supposition that a defect in the genesis of something is evidence that discredits the thing itself) need be no fallacy. A causal account of the origins and maintenance of belief can undermine that belief's rational warrant." (Sterelny 2006) Conversely, if scientists had been utterly baffled by the existence of religious phenomena, and if their attempts to reconstruct its natural origins had been frustrated time and again, this would have counted in favor of supernatural origins (Fishman 2009; Boudry et al. 2010). Of course, tracing the psychological roots of religious belief does not positively demonstrate that all religions are false. Conclusive proof is hard to come by for fallible creatures such as ourselves, even with the best tools of science at our disposal.

Take the discovery of the ideomotor effect, the subtle and unconscious muscle movements that people make without being aware of them. Skeptics of the paranormal invoke the ideomotor effect to account for seemingly paranormal phenomena such as Ouija board séances, where people are placing their hand above a glass or cup and "mediate" the message of a spirit being, by moving the glass across a circle of letters. People seem honest when they report that they are not

Footnote 12 continued

existence (or for ghosts or witches), it hardly matters how belief in the supernatural originated. But there are no such water-tight arguments, and religious belief is typically defended on the basis of spiritual experiences (encountering God), or intuitions about design, improbability and fine-tuning. Given that those arguments have no secure basis in logic or evidence, and we have a good evolutionary explanation for why they seem so compelling (even if totally wrong), the most parsimonious explanation is that no such supernatural beings exist. Again, bringing up the "fallacy" charge detracts from the real probative value of psychological accounts of belief. 
consciously steering the glass, but meaningful sentences appear anyhow. Is the skeptic guilty of the genetic fallacy when he discredits the existence of spirit beings by pointing to the psychological causes of the Ouija effect?

To spell out this argument in probabilistic terms, take yet another case from pseudoscience: claims of out-of-body experiences. The ability of neurobiologists to induce such experiences in the lab raises the likelihood of natural explanations for occurrences outside the lab. In addition, we know that we can provoke OBE's by way of causes that are hardly exotic, i.e., that are likely to occur outside the lab as well, for example sensory deprivation, lack of oxygen, psychotropic drugs, hypnosis etc. This raises the prior probability of natural causes leading up to OBEs. Again, a counterfactual scenario can drive home this point. The case against the paranormal explanation of OBEs would be less convincing if experimenters were unable to induce OBEs in the lab, or if they could only do so using exotic forms of neurostimulation that are unlikely to occur in more natural settings. It is not merely the fact that OBEs are reproduced in the lab that undermines the paranormal explanation. Spooky explanations become superfluous, just as the spirit hypothesis becomes little more than a remote, logical possibility once we understand the mechanisms of the ideomotor effect (in both cases, of course, further tests can be carried out to investigate the rival hypotheses).

In many instances where the specter of the "genetic fallacy" is raised, it turns out to be a red herring, an illegitimate shortcut to dismiss a valuable argument. This perfectly illustrates the problem with the practice of labeling some arguments as "fallacies". The label itself, often italicized or capitalized, suggests some sort of established philosophical result, which would make any further intellectual effort unnecessary. The message is: we all know that there is such a thing as the genetic fallacy, and we all know it's wrong. The religious apologist William Lane Craig, in attacking atheist arguments on the psychological origins of religion, called it an "elementary logical fallacy known to every intro-to-philosophy student". ${ }^{13}$ End of discussion. But careful analysis shows that many forms of "genealogical critiques" are perfectly reasonable (Ward 2010). In fact, it is fair to say that the fallacy is wholly in the eye of the beholder. And that's what happens when people play the fallacy game.

\subsection{A Few Other Examples}

Many argument schemas constituting alleged fallacies, as we have seen, can actually accommodate perfectly acceptable forms of reasoning. In all these cases, fallacy labels fail to capture the distinction between good and bad forms of reasoning, and hence are misnomers, distracting from real issues. Other examples could be given: the "naturalistic fallacy", for example, committed when one infers what is good from what is natural, is sometimes a sensible presumption. If the good is not informed by the world out there, where exactly does it come from, as Dennett asked (1996)? When talking about health and body, for example, natural biological functions have some normative import. Take the following argument: "feeding

13 "Is God Hardwired into Your Brain?" https://www.youtube.com/watch?v=c0zD0bQbkwE. 
vegetables to a cat is bad, because it's not natural". Would anyone argue that this is fallacious? At worst, the argument is somewhat elliptic, relying on a number of hidden premises (cats are carnivores, they haven't had a vegetarian diet for millions of years, so their metabolism is ill-suited for digesting vegetables). But almost all good arguments in everyday conversations contain assumptions and hidden premises. To spell them all out would be cumbersome indeed. Or take the argumentum ad verecundiam. Contrary to what the fallacy label suggests, deference to experts is often rational (provided certain conditions are fulfilled, see Wagemans 2011), and even a default heuristic in many everyday affairs. As with all heuristics, it is fallible. It can slip into an uncritical deference to anything dictated by an (alleged) expert. Much depends on the relevant area of expertise, the track record of the expert, the number of concurring and opposing experts, etc. (Walton 1995). The idea that appeals to authority are somehow formally deficient, however, as the weighty name argumentum ad verecundiam suggests, would undermine the whole social fabric of knowledge. Much of what we think we know is based on what we learn from others.

With regard to the "straw man" fallacy, Aikin and Casey have concluded that many forms of straw man reasoning may be acceptable moves to focus or redirect a discussion. Diagnosing the fallacy on formal grounds is impossible, because "there are formally similar maneuvers in dialogue that contribute positively to rational resolution of a dispute" (Aikin and Casey 2011: 104). If the move is fallacious at all, it is because of the dialectical and pragmatic context of the discussion. Lewinski (2011) reconstructs straw men reasoning as a harsh but reasonable strategy in informal and/or adversarial debates.

Fallacy theorists nowadays acknowledge that many "fallacies" have close cousins that are acceptable inferences, but when it comes to locating the demarcation line separating good from bad reasoning, typically they can offer little more than warnings against overselling or putting too much weight on an argument. In his classic study on fallacies, Douglas Walton writes: "[Fallacies] are arguments that in principle have some degree of correctness but are pressed forward in a given case too aggressively, or in an unwarranted fashion, masquerading as a much more powerful type of argument." (Walton 1995: 97) This is not very helpful: too much of anything is bad, by definition. Elsewhere, Walton wrote that "many of the traditional so-called fallacies are not fallacies at all, but are arguments that can sometimes be reasonable, as instances of plausible reasoning, yet can in some cases be subject to criticism for specific failures" (Walton 1988: 250). But if the strengths and weaknesses of these arguments depend on the specific context, and not on their exhibiting a certain argument structure, why insist on taxonomic nomenclature?

To briefly reiterate the Fallacy Fork: if construed as deductive, non-defeasible inferences (or even strong inductive ones), fallacies are cut-and-dried, but rarely found in real life. If construed as presumptively supporting a conclusion, or providing circumstantial evidence for a claim, or simply shifting the burden of proof to the other party, then we find plenty of examples in real life, but we lose grip on the normative dimension. Instances of fallacies are formally or logically equivalent to forms of reasoning that are both intuitively sound and widely used. 
Interestingly, cognitive psychologists have also started to question the prevalence of reasoning fallacies in everyday life. In their research on the conjunction fallacy, for example, Daniel Kahneman and Amos Tversky had attributed a violation of the conjunction rule to their subjects. ${ }^{14}$ According to this rule, the conjunction of two events is always less probable than either of its conjuncts. Further research, however, suggested that Kahneman's interpretation glossed over subtle conversational implicatures used by subjects, which made the conjunction rule irrelevant or moot. Different versions of the experiment, which narrow down interpretations to the one where the rules of mathematical probability apply, seem to make the alleged "fallacy" disappear. In a similar vein, other forms of irrationality, such as preference reversals, sunk cost fallacies, and base rate fallacies, are now increasingly revisited in ways that are more sensitive to the ecological complexity of human reasoning (Gigerenzer 2008; Gigerenzer et al. 2011). Previous research seems to have construed human reasoning in a rigid and uncharitable way, prematurely accusing people of committing fallacies (Boudry et al. 2015). This is similar to the point we are making here: what appears to be a straightforward fallacy at first blush, may turn out to be quite elusive on closer inspection, as more details are filled in. Fully-fledged fallacies are harder to find in real life than is commonly assumed.

\section{The Fallacy Fork in Pragma-Dialectics}

At this point, a reader well versed in argumentation theory may charge us in turn with a number of fallacies. Is the Fallacy Fork not an instance of a false dilemma, by excluding a reasonable middle way? Aren't we knocking down a straw man by focusing all our efforts on outdated conceptions of fallacies, ignoring the more recent and sophisticated accounts? And is that in its turn not a shameless form of cherry picking? The cherry that we have conveniently failed to pick out, because it does not fit our theoretical basket, would be the pragma-dialectical approach to fallacies (van Eemeren and Grootendorst 1984, 1992, 2004). This approach is radically different from the standard treatment and, insofar as it does not even attempt to construe fallacies as inference schemes, would seem to neatly escape either branch of our fork. As briefly mentioned in the Introduction, pragmadialectics defines fallacies with respects to the procedural rules that are supposed to regulate an ideal model of dialogue aimed at solving a difference of opinion, i.e., a critical discussion. As van Eemeren puts it, "The term fallacy is thus systematically

14 Subjects were given the following scenario:

Linda is 31 years old, single, outspoken, and very bright. She majored in philosophy. As a student, she was deeply concerned with issues of discrimination and social justice, and also participated in anti-nuclear demonstrations.

Which is more probable?

(A) Linda is a bank teller.

(B) Linda is a bank teller and is active in the feminist movement.

Seemingly in violation with the conjunction rule, the majority of subjects answered B. For a discussion of the conversational implicatures ignored by Kahneman and Tversky (in particular Grice's maxim of relevance), see Hertwig and Gigerenzer (1999). 
connected with the rules for critical discussion and defined as a speech act that prejudices or frustrates efforts to resolve a difference of opinion" (2001: 158, emphasis in the original). So, is pragma-dialectics immune to the Fallacy Fork?

We don't think so. First, consistent with the meta-theoretical principle of functionalization (van Eemeren et al. 2014: 523-524), a critical discussion is defined as an ideal model, which is meant to have important applications to real life arguments, but for which no one-to-one correspondence with reality is ever claimed or sought. As a result of this, the pragmatic approach does not so much escape the Fallacy Fork as run up against its own version of it. Second, consistent with the meta-theoretical principle of socialization (van Eemeren et al. 2014: 524-525), argumentation is always conceived as a social activity in pragma-dialectics, involving at least two parties and with an emphasis on the roles of the "protagonist" and the "antagonist" in a dialogue. Although this approach allows the pragmadialectical approach to solve some of the puzzles in the Standard Treatment (e.g., begging the question), many alleged fallacies are epistemological in nature, occur outside social contexts, and are invariant across different dialectical contexts. As a result, dialectical factors often fail to account for differences in argumentation strength, leaving the original Fallacy Fork unscathed. Let us treat these two points in order.

\subsection{The Ideal of a Critical Discussion}

The procedural definition of fallacy in pragma-dialectics, though perfectly intelligible, is theoretically dependent upon the idealized notion of a critical discussion and its rules (for a criticism of this view, see Woods 2004). Even if we assume, for argument's sake, that the pragma-dialetical approach successfully demarcates epistemically suspect moves, these will be limited to concrete situations where the conditions of a critical discussion are fulfilled. This is the first side of the (new) Fallacy Fork, as applied to pragma-dialectics. To find more real-life instances of argumentations that are analyzable through the pragma-dialectical approach, we could relax the standards of the critical discussion, taking into account the complexities and ambiguities of real life. Again, however, this solution risks losing our normative grip on the question of what is a fallacy and what is not (second side of the Fallacy Fork).

Pragma-dialecticians are well aware of the problem of idealization, and they have clearly articulated the relationship between the ideal model of a critical discussion and argumentative reality: in a nutshell, they claim that the ideal model can serve heuristic, analytic, and critical functions in dealing with real life cases (van Eemeren et al. 2014: 528-529). The heuristic value consists of using the theory to generate well-behaved argumentative practices, the analytic function is served by providing a frame of reference to segment and assess different stages in an argumentative exchange and the moves within each stage, and the critical aspect boils down to measuring the quality of the actual practice against the backdrop of the normative standard. While the usefulness of pragma-dialectics in a variety of communicative domains is well documented (for a quick overview, see van Eemeren et al. 2014: 581-586), its merits largely depend on deliberately narrowing the scope of what is 
considered "argumentation", with respect to the pre-theoretical understanding of the notion, and thus missing out on much of what happens in real life.

Let's clarify this point with a simple example. We can all agree that the function of many televised debates between opposing advocates (e.g., the Presidential Debates in the US prior to an election) is, most emphatically, not to solve a difference of opinions between the parties; on the contrary, participants in such a debate highlight their differences of opinion, as a means to the real end of the game, which is to win over the majority of the audience to one's standpoint. By definition, this is not a critical discussion, and thus the pragma-dialectical notion of fallacy holds no sway here. Now, should Presidential candidates be criticized for failing to live up to the ideal of a critical discussion? We don't see on what grounds such an accusation would make sense. Given the political function of a presidential debate, firmly holding one's grounds and maintaining distance with one's opponent seems a perfectly reasonable strategy to pursue, and a legitimate one too.

Of course, there is nothing theoretically wrong in stipulating that this is not an instance of argumentation, but rather some form of rhetorical engagement. The problem is that this stipulation moves sharply away from ordinary intuitions: both laymen and debate experts regard Presidential Debates as exemplary cases of argumentation. Yet, should pragma-dialectics consider these cases as instances of a critical discussion, this would mischaracterize the situation and lead to forced and farfetched conclusions. Most moves would come out as fallacious, in spite of their eminent reasonableness, given the actual function of the activity. The notion of strategic maneuvering (van Eemeren and Houtlosser 2002, 2006) would do little to remedy the problem, since the difficulty here is not in striking some balance between the proper function of the dialogue and the personal goals of the parties, but rather to correctly identify its proper function to begin with. ${ }^{15}$ Even televised Presidential debates, with their streamlined format and strict rules of engagement, don't wear their argumentative function on their sleeve. Participants may pretend to the outside world that the purposes of the debate is just to rationally resolve society's problems, but everyone understands that, at least to some unspecified extent, the ambition of both parties is to score political points, defend the party line and win the upcoming election. The purpose of many real-life discussions is, if anything, even less straightforward.

\subsection{Epistemological Fallacies}

Even when we narrow our focus to the types of dialogues that approach the ideal of a critical discussion, it is not clear if the pragma-dialectical approach can escape the original Fallacy Fork for most of the fallacies we analyzed above. This is because, even after we have cast fallacies in a dialectical context, treating them as speech acts at a certain stage in a critical discussion rather than abstract argumentation schemes, it is still not clear whether we can discriminate acceptable from suspect

\footnotetext{
15 As Zarefsky notes: "It is difficult to evaluate strategic maneuvering in political argumentation ... because the activity types dictate wide latitude for the arguers, so there are few cases of unquestionable derailment" (2008: 317).
} 
forms of reasoning. The fallacy of post hoc ergo propter hoc, for example, appears unanalyzed as a violation of the pragma-dialectical discussion rule stipulating that "appropriate inference schemes" need to be "correctly applied" (van Eemeren and Grootendorst 1995). But this runs up against the same kinds of considerations that we mentioned before, leaving most of the demarcation work undone. As Hahn and Oaksford (2007) have shown, two formally identical post hoc arguments in the same stage of a critical discussion can still have differential strengths, depending on various probabilistic factors: "individual arguments vary systematically in strength within a fixed [dialectical] context" (Hahn and Oaksford 2007: 727).

The deeper reason for this problem is that the alleged flaws of the four fallacies we discussed above, as well as many others in the standard list, are not primarily social in nature. They all deal with alleged mistakes of reasoning that can be easily committed, and presumably often are, in utter isolation from others. The selfimposed restriction in scope of the pragma-dialectical approach to the social and dialectical domain is perfectly understandable, in view of its stated theoretical aims, but this limits the application of the approach to present purposes, since critical thinking needs not always be understood as part of some social engagement. Moreover, even the more "social" types of fallacies, such as ad hominem, ad verecundiam and ad populum arguments, are naturally seen as epistemological categories and can thus be applied to individual reasoning: should I assess certain claims based on the personal characteristics of their source, the say-so of experts, or popular opinion? As discussed, contextual features are essential here, but they are not necessarily dialogical. And when charges of fallaciousness are taken out of a dialogical context (more precisely, a dialogue that can be meaningfully associated with the model of a critical discussion), pragma-dialectics has no guidance to offer.

\section{Rhetorical and Dialectical Problems}

Not all fallacies appear in a social context. To the extent that there is a dialectical dimension, however, the Fallacy Fork becomes even more intractable. According to Aristotle, fallacies are deceptive or sophistical moves in a discussion, not simply honest errors of inference or lapses of judgment (Hamblin 1970; Walton 1995: 240-249). Their underlying rationale seems to consist of rhetorical manipulation and counterfeit (possibly including forms of self-deception). This psychological component, which has been neglected for some time due to the dominance of "deductive chauvinism" in logic and philosophy (Johnson 1987: 243), is now being reappraised in pragmatic theories of fallacies. ${ }^{16}$ In their deductive or non-defeasible guises, as the Fallacy Fork points out, most of the so-called fallacies are transparently invalid. Indeed, from a dialectical point of view, they would probably not impress your average audience, and are therefore unlikely to crop up during everyday conversation, let alone in an intelligent debate. Persuasive strategies that

\footnotetext{
16 Van Eemeren and Grootendorst (2004: 175), however, are critical of expressions such as "appearance of validity", which they deem "subjective and vague". This is unfortunate, as we think this psychological component is essential in understanding the appeal of fallacies.
} 
are patently fallacious (for example: brute threats or blunt ad hominems) hardly deserve the attention of argumentation theorists, because they have a limited capacity to deceive even gullible audiences. The stock-in-trade "fallacies" that are prevalent enough to make it into the standard lists are the ones that have a ring of plausibility in the eyes of most people, because they are close cousins to good forms of reasoning: to use Woods' terminology (2013: 135), they follow the EAUI conceptualization, according to which fallacies are Errors that are Attractive, Universal, and Incorrigible. But that, of course, was precisely the problem to begin with. The project of demarcating fallacies sits uncomfortably with one of their central characteristics: their power to deceive us by mimicking good arguments (Lewiński 2011; Boone 2002).

Walton (2010b) has connected the theory of fallacies with psychological research on reasoning heuristics. To the extent that an argument is fallacious, it often mimics an argument pattern that, by and large, is pretty reasonable. Walton used the concept of a heuristic as a mediator between a fallacy and a defeasible argumentation scheme (Walton 2010b). This form of mimicry has an irreducible psychological component. In order to manipulate the audience into swallowing a given conclusion, the speaker needs to present arguments that are superficially similar to valid ones (Mercier and Sperber 2011).

In line with this element of deception, and further widening the Fallacy Fork, is the fact that many potential fallacies are made in a whiff of plausible deniability. If, in the course of a debate on the efficacy of some drug, I discreetly point out that my opponent is "on the payroll of pharmaceutical company X", I am not affirming but merely suggesting that, say, we should take his arguments with a grain of salt. Indeed, I am not even making so much as an argument in the first place. Am I committing a fallacy? Perhaps not if the argument is construed in its weak, presumptive sense. And even less so if I can plausibly maintain that I did not intend to make an argument in the first place (Walton 1995: 216). As John Stuart Mill wrote in A System of Logic (Chap. 2, Sect. 3): "it is not in the nature of bad reasoning to express itself thus unambiguously. When a sophist, whether he is imposing on himself or attempting to impose on others, can be constrained to throw his sophistry into so distinct a form, it needs, in a large proportion of cases, no further exposure." (Mill 2009: 487) Many real-life instances of so-called fallacies take on the form of innuendo and suggestion, bearing out the point that few people would fall for them if they were spelled out more explicitly. Fallacies exploit the implicitness of language, both with respect to content and illocutionary force (Van Eemeren and Grootendorst 1987, 2004). The audience is invited to draw its own conclusions, but the speaker can plausibly deny that she suggested anything of the kind.

This is the Fallacy Fork all over again, with a rhetorical twist: in their pure, undisguised structure, traditional fallacies wouldn't be persuasive at all, which is exactly why they are rarely found in such distilled form; but when so-called fallacies are dressed up in more seductive garb, it is no longer easy to pin down their alleged flaws, since much is left to interpretation and multiple exit strategies remain open to the offender. When an attempt to provide a well ordered classification of dialectical infractions and mistakes of reasoning ends up in such dire straits, there is 
probably something wrong in the basic assumptions underlying the whole enterprise (Woods 2013).

As we noted, many logic textbooks and skeptical treatments of pseudoscience contain a section on fallacies, with the list of the usual suspects, but it is notable that the concepts are rarely put to work in actually dealing with pseudoscience (Massey 1981). If this happens at all, the reference to fallacies is perfunctory or superficial. Indeed, because of the vague and uninformative nature of many textbook fallacies, they easily lend themselves to abuse. We already mentioned the reflexive resort to the "genetic fallacy" in discussions about the cognitive and evolutionary explanations of religion. But even outright pseudoscientists find it easy to press the traditional "fallacies" into their service. For example, in his Defeating Darwinism, Philip Johnson turns Carl Sagan's concept of the baloney detection kit against advocates of evolutionary theory, accusing them of appeals to authority ( $\mathrm{d}$ verecundiam), ad hominem arguments and straw men (Johnson 1997). Of course, ID advocates also happily resort to the genetic fallacy when the religious roots of their movement are being exposed. ${ }^{17}$ Climate denialists flag the post hoc ergo propter hoc fallacy when scientists attribute global warming to human carbon emissions, and they cry "ad populum" when someone brings up the consensus opinion of expert panels such as the IPCC. ${ }^{18}$ Two can play that fallacy game.

\section{Discussion}

In the beginning of this paper, we forged a connection between the demarcation problem of fallacy theory and the traditional demarcation project in philosophy of science. Is there an analogue for the Fallacy Fork with respect to the science/ pseudoscience demarcation? Most philosophers of science nowadays agree that there is no silver bullet to distinguish science from pseudoscience. It is also widely acknowledged that a purely formal criterion, based on the propositional structure of the theory and its relation with the world, is insufficient to capture the distinction between genuine science and its rivals. Philosophers, just as argumentation theorists, have enriched their understanding of their subject with psychological and social considerations. What makes the term pseudoscience useful, despite the absence of a clear dividing line, is that there is no shortage of instances that fall clearly on either side of the (fuzzy) boundary. Evolutionary theory, thermodynamics and quantum mechanics are all solid sciences, whereas astrology, creationism and homeopathy are not even close. In contrast with fallacy theory, therefore, finetuning the demarcation criteria in philosophy of science has not hampered our ability to identify genuine, real-life examples of pseudoscience.

Compare this with the Fallacy Fork in argumentation theory. By making our diagnostic criteria sensitive to real-life argumentative context-including the level

\footnotetext{
17 For example, Menuge (2004: 36) on ID critic Barbara Forrest: "[o]ne cannot show that ID is false or fruitless by pointing to the religious (or political) beliefs of its proponents".

18 The whole standard list of fallacies, with more unusual examples, can be found on http://www. conservapedia.com/Logical_fallacy.
} 
of claimed support, tacit premises, probabilistic considerations, conversational rules and dialectical context-we seem to lose grip on the question as to what separates fallacies from good forms of inference. Because of the destructive dilemma which we termed the Fallacy Fork, our taxonomy loses much of its appeal, which was to allow for argumentative short-cuts, identifying structural features of arguments that are fallacious regardless of the specific context.

The problem runs deeper than the shortcomings of the standard logical approach, and cannot be simply solved by a pragmatic turn. Our very labeling practices suggest that reasoning defects can be gleaned from the respective labels: appeal to authority, ad hominem, ad verecundiam, ad ignorantiam, etc. (Walton 1995: 208-211). But this is highly misleading. As we have shown, the quick charge of committing a fallacy is often nothing more than a rhetorical gambit to evade whatever issue is at stake. Playing the "fallacy" game either means dismissing good arguments without a fair hearing, or attacking bad arguments with equally bad diagnoses. If normative distinctions cannot be made on the level of abstractness that fallacy taxonomies suggests, is it time to drop the diagnostic label of "fallacy" altogether? Or is our Fallacy Fork an instance of the "false dilemma" fallacy (Tomic 2013)? But then again, how to distinguish between proper and spurious dilemmas?

By way of conclusion, let us offer a modest constructive proposal. As long as the notion of fallacy conveys the presumption of identifying something erroneous, without being grounded in a theory capable of avoiding the Fallacy Fork across various contexts, its use in everyday conversation is akin to name callingoccasionally effective for practical purposes, but rarely informative and basically unfair. If we are right, no universal way out of the Fallacy Fork is forthcoming. Still, we might want to relax the other assumption just mentioned, that is, the idea that fallacy is "a dirty word". What if the notion of fallacy, instead of being wielded like the sword of judgment against opponents, was employed for more amicable purposes, e.g., suggesting ways to clarify arguments that, without being necessarily flawed, stand in need of substantial elaboration?

As we discussed, and as is often emphasized in modern treatments of fallacy, whether something ends up being fallacious or not depends on a variety of factors, most of which are not immediately specified when a potentially fallacious move occurs. This makes the tradition of "crying fallacy" highly problematic, but it does leave open the possibility of using (what is currently known as) fallacy theory as a blueprint to make real progress in the discussion. For instance, when an ad hominem attack is suspected, it is time to clear the air and candidly ask what other conditions must be in place, in order for a certain personal trait of the arguer to have a bearing on the matter at hand. This might evolve in a variety of ways: the original "adhominer" may in fact clarify the reasons that are supposed to connect the person's features with the credibility of his/her claims, and then the dialogue evolves in a perfectly reasonable way; alternatively, the whole attack may be denied ("I never meant to criticize the argument, I was just voicing some facts about this particular source..."), providing evidence of rhetorical contortions by the original accuser; or else, a full-frontal ad hominem attack may be revealed, thus proving that indeed there was something fishy in the move itself. Either way, the point is not to launch 
an outright accusation of fallaciousness early on, but rather to use fallacy theory to guide us towards a better understanding of what was the original argument and what are the grounds of its reasonableness (or lack thereof).

Nice as this project may sound, there is still bad news for fallacy buffs. Unfortunately, the label "fallacy" is not only superfluous, but even harmful to such a constructive use of critical examination. ${ }^{19}$ The same applies to all the usual paraphernalia of fallacy theory, with its abundance of resounding labels: they do little theoretical work, and their main intended function is to scare into submissions alleged perpetrators of dire reasoning mistakes-which, as we saw, are often no mistakes at all. If we want to move towards a more productive use of rational criticism (which is not to say less effective or more timid), we need to rid ourselves of this outdated arsenal. As it turns out, in fallacy theory, the theory is usually quite good, in some cases even excellent: it's this obsession with fallacies that has to go.

Acknowledgments The research of the first author was supported by the Research Foundation Flanders (FWO). The second author's work was supported by the project PRISMA-Interoperable Cloud Platforms for Smart-Government, funded by the Italian Ministry of Education, University and Research (MIUR-PON). The third author was supported by the K.D. Irani fund for Philosophy of Science at the City College of New York. We would like to thank Jan Verplaetse, Danny Praet and John Teehan for useful comments on earlier drafts of this paper.

\section{References}

Aikin, S.F., and John Casey. 2011. Straw men, weak men, and hollow men. Argumentation 25(1): 87-105.

Alcock, J. 2011. Back from the future: Parapsychology and the Bem affair. Skeptical Enquirer 35(2): 31-39.

Barrett, J.L. 2007. Cognitive science of religion: What is it and why is it? Religious Compass 1(6): $768-786$.

Barth, E.M., and E.C.W. Krabbe. 1982. From axiom to dialogue: A philosophical study of logics and argumentation. Berlin/New York: de Gruyter.

Bering, J. 2012. The belief instinct: The psychology of souls, destiny, and the meaning of life. New York: WW Norton \& Company.

Boone, D.N. 2002. The cogent reasoning model of informal fallacies revisited. Informal Logic 22(2): 93-111.

Boudry, M., and J. De Smedt. 2011. In mysterious ways: On the modus operandi of supernatural beings. Religion 41(3): 517-535.

Boudry, M., S. Blancke, and J. Braeckman. 2010. How not to attack intelligent design creationism: Philosophical misconceptions about methodological naturalism. Foundations of Science 15(3): $227-244$.

Boudry, M., and J. Braeckman. 2011. Immunizing strategies \& epistemic defense mechanisms. Philosophia 39(1): 145-161.

\footnotetext{
19 A similar conclusion is reached by Hahn and Oaksford (2006, 2007), following a partially different path, adopting the Bayesian approach to informal fallacies: as these authors emphasize, the value of this framework is not merely descriptive, but also (and mostly) normative. Their empirical findings suggest that people reliably discriminate between truly fallacious arguments and perfectly cogent "fallacies", and they do so consistently with an underlying normative standard-that is, Bayesian conditionalization. Crucially, this standard provides normative grounds for argument validity without invoking any dialectical complication (thus it is arguably more parsimonious than other modern treatments of fallacies), but also without assigning any explanatory role to the notion of "fallacy". Thus, as predicted, Bayesian argumentation walks out of the Fallacy Fork by ridding itself from the notion of fallacy altogether-which is precisely what we suggest all theories of argumentation should do.
} 
Boudry, M., M. Vlerick, and R.T. McKay. 2015. Can evolution get us off the hook? Evaluating the ecological defence of human rationality. Consciousness and Cognition, 33, 524-535. doi:10.1016/j. concog.2014.08.025.

Brinton, A. 1995. The ad hominem. In Fallacies: Classical and contemporary readings, ed. H.V. Hansen, and R.C. Pinto, 213-222. University Park: The Pennsylvania State University Press.

Carroll, R.T. 2000. Becoming a critical thinker: A guide for the new millennium. Boston, MA: Pearson Custom Publishing.

Copi, I.M., and C. Cohen. 1998. Introduction to logic. New York: Prentice-Hall Inc.

Cummings, L. 2002. Reasoning under uncertainty: The role of two informal fallacies in an emerging scientific inquiry. Informal Logic 22(2): 113-136.

DiCarlo, C. 2011. How to become a really good pain in the ass: A critical thinker's guide to asking the right questions. Amherst, N.Y.: Prometheus Books.

Dennett, D.C. 1996. Darwin's dangerous idea: Evolution and the meanings of life. New York: Simon and Schuster.

Finocchiaro, M.A. 1981. Fallacies and the evaluation of reasoning. American Philosophical Quarterly 18(1): 13-22.

Fishman, Y. 2009. Can science test supernatural worldviews? Science \& Education 18(6): 813-837.

Galperin, A., and M.G. Haselton. 2012. Error management and the evolution of cognitive bias. In Social thinking and interpersonal behavior, ed. J.P. Forgas, K. Fiedler, and C. Sedikedes, 45-64. New York: Psychology Press.

Gardner, M. 1957. Fads and fallacies in the name of science. New York: Dover Publications.

Gigerenzer, G. 2008. Rationality for mortals: How people cope with uncertainty. Oxford: Oxford University Press.

Gigerenzer, G., R. Hertwig, and T. Pachur. 2011. Heuristics: The foundations of adaptive behavior. New York: Oxford University Press.

Grünbaum, A. 1979. Is Freudian psychoanalytic theory pseudo-scientific by Karl Popper's criterion of demarcation? American Philosophical Quarterly 16(2): 131-141.

Hahn, U., and M. Oaksford. 2006. A Bayesian approach to informal argument fallacies. Synthese 152(2): 207-236.

Hahn, U., and M. Oaksford. 2007. The rationality of informal argumentation: A Bayesian approach to reasoning fallacies. Psychological Review 114(3): 704-732.

Hamblin, C.L. 1970. Fallacies. London: Methuen.

Hansen, H.V., and R.C. Pinto. 1995. Fallacies: Classical and contemporary readings. University Park, PA: The Pennsylvania State University Press.

Hart, D.B. 2013. The experience of god: Being, consciousness, bliss. New Haven: Yale University Press.

Hertwig, R., and G. Gigerenzer. 1999. The conjunction fallacy revisited: How intelligent inferences look like reasoning errors. Journal of Behavioral Decision Making 12: 275-306.

Jacobs, D.M. 1998. The threat: The secret agenda-What the aliens really want ... and how they plan to get it. New York: Simon \& Schuster.

James, W. 2008. The varieties of religious experience: A study in human nature. Rockville: ARC Manor.

Johnson, P.E. 1997. Defeating Darwinism by opening minds. Downers Grove: InterVarsity Press.

Johnson, R.H. 1987. The blaze of her splendors: Suggestions about revitalizing fallacy theory. Argumentation 1(3): 239-253.

Jong, J., and A. Visala. 2014. Evolutionary debunking arguments against theism, reconsidered. International Journal for Philosophy of Religion 76(3): 243-258.

Kahane, G. 2010. Evolutionary debunking arguments. Noûs 45(1): 103-125.

Kahneman, D., P. Slovic, and A. Tversky. 1982. Judgment under uncertainty: Heuristics and biases. Cambridge: Cambridge University Press.

Kennedy, J.E. 2003. The capricious, actively evasive, unsustainable nature of psi: A summary and hypotheses. The Journal of Parapsychology 67(1): 53-75.

Krabbe, Erik C.W. 2009. Book review of Christopher W Tindale, 'Fallacies and argument appraisal'. Argumentation 23(1): 127-131.

Laudan, L. 1982. Commentary: Science at the bar-causes for concern. Science, Technology and Human Values 7(41): 16-19.

Lewiński, M. 2011. Towards a critique-friendly approach to the straw man fallacy evaluation. Argumentation 25(4): 469-497.

Macagno, F. 2013. Strategies of character attack. Argumentation 27(4): 369-401. doi:10.1007/s10503013-9291-1. 
The Fake, the Flimsy, and the Fallacious: Demarcating...

Mack, J.E. 1995. Abduction: Human encounters with aliens. London: Simon and Schuster.

Massey, G.J. 1981. The fallacy behind fallacies. Midwest Studies in Philosophy 6(1): 489-500.

Menuge, A. 2004. Who's afraid of ID? A survey of the intelligent design movement. In Debating design, ed. W. Dembski, and M. Ruse, 32-51. Cambridge: Cambridge University Press.

Mercier, H., and D. Sperber. 2011. Why do humans reason? Arguments for an argumentative theory. Behavioral and Brain Sciences 34(2): 57-74.

Mill, J.S.S. 2009. System of logic ratiocinative and inductive. New York: Cosimo.

Nieminen, P., and A. Mustonen. 2014. Argumentation and fallacies in creationist writings against evolutionary theory. Evolution: Education and Outreach 7(1): 11.

Paglieri, F. 2014. Trust, argumentation and technology. Argument and Computation 5(2-3): 119-122.

Pigliucci, M., and M. Boudry. 2013a. Prove it! The burden of proof game in science vs. pseudoscience disputes. Philosophia 42(2): 487-502.

Pigliucci, M., and M. Boudry (eds.). 2013b. Philosophy of pseudoscience: Reconsidering the demarcation project. Chicago: University of Chicago Press.

Pinto, R.C. 1995. Post hoc ergo propter hoc. In Fallacies: Classical and contemporary readings, ed. Hans V. Hansen, and Robert C. Pinto, 302-311. University Park: The Pennsylvania State University Press.

Ritchie, S.J., W. Richard, and C.C. French. 2012. Failing the future: Three unsuccessful attempts to replicate Bem's 'retroactive facilitation of recall' effect. PLOS ONE 7(3): e33423.

Sagan, C. 1996. The demon-haunted world: Science as a candle in the dark. New York: Random House.

Salmon, W.C. 1984. Logic, 3rd ed. Englewood Cliffs: Prentice-Hall.

Shermer, M. 1997. Why people believe weird things: Pseudoscience, superstition, and other confusions of our time. New York, NY: Freeman.

Sterelny, K. 2006. Escaping illusion? American Scientist 94(5): 461-463.

Tindale, C.W. 2007. Fallacies and argument appraisal. Cambridge: Cambridge University Press.

Tomic, T. 2013. False dilemma: A systematic exposition. Argumentation 27(4): 347-368. doi:10.1007/ s10503-013-9292-0.

Van Bendegem, J. 2013. Argumentation and pseudoscience. The case for an ethics of argumentation. In Philosophy of pseudoscience: Reconsidering the demarcation problem, ed. M. Pigliucci, and M. Boudry, 287-304. Chicago: University of Chicago Press.

van Eemeren, F.H. 2001. Fallacies. In Critical concepts in argumentation theory, ed. Frans H. van Eemeren, 135-164. Amsterdam: Amsterdam University Press.

van Eemeren, F.H., and P. Houtlosser. 2002. Strategic maneuvering: Maintaining a delicate balance. In Dialectic and rhetoric: The warp and woof of argumentation analysis, ed. F.H. van Eemeren, and P. Houtlosser, 131-159. Dordrecht: Kluwer.

van Eemeren, F.H., and Peter Houtlosser. 2006. Strategic maneuvering: A synthetic recapitulation. Argumentation 20(4): 381-392.

van Eemeren, F.H., and R. Grootendorst. 1984. Speech acts in argumentative discussions. A theoretical model for the analysis of discussions directed towards solving conflicts of opinion. Berlin/Dordrecht: de Gruyter/Foris.

van Eemeren, F.H., and R. Grootendorst. 1987. Fallacies in pragma-dialectical perspective. Argumentation 1(3): 283-301.

van Eemeren, F.H., and R. Grootendorst. 1992. Argumentation, communication, and fallacies. A pragmadialectical perspective. Hillsdale: Lawrence Erlbaum.

van Eemeren, F.H., and R. Grootendorst. 1995. The pragma-dialectical approach to fallacies. In Fallacies: Classical and contemporary readings, ed. H.V. Hansen, and R.C. Pinto, 130-144. Pennsylvania: The Pennsylvania State University Press.

van Eemeren, F.H., and R. Grootendorst. 2004. A systematic theory of argumentation: The pragmadialectical approach. Cambridge: Cambridge University Press.

van Eemeren, F.H., Bart Garssen, E.C.W. Krabbe, A.F.Snoeck Henkemans, B. Verheij, and J.H.M. Wagemans. 2014. Handbook of argumentation theory. Berlin: Springer.

Wagemans, J.H.M. 2011. The assessment of argumentation from expert opinion. Argumentation 25(3): 329-339.

Wagenmakers, E.-J., R. Wetzels, D. Borsboom, and H.L.J. Van Der Maas. 2011. Why psychologists must change the way they analyze their data: The case of psi: Comment on Bem (2011). Journal of Personality and Social Psychology 100(3): 426-432.

Walton, D.N. 1988. Burden of proof. Argumentation 2(2): 233-254.

Walton, D.N. 1989. Dialogue theory for critical thinking. Argumentation 3: 169-184. 
Walton, D.N. 1992. Nonfallacious arguments from ignorance. American Philosophical Quarterly 29(4): 381-387.

Walton, D.N. 1995. A pragmatic theory of fallacy. Tuscaloosa: University of Alabama Press.

Walton, D.N. 1999. The appeal to ignorance, or argumentum ad ignorantiam. Argumentation 13(4): 367-377.

Walton, D.N. 2010a. Formalization of the ad hominem argumentation scheme. Journal of Applied Logic 8(1): 1-21. doi:10.1016/j.jal.2008.07.002.

Walton, D.N. 2010b. Why fallacies appear to be better arguments than they are. Informal Logic 30(2): 159-184.

Ward, Andrew C. 2010. The value of genetic fallacies. Informal Logic 30(1): 1-33.

Woods, J., and D. Walton. 1977. Post hoc, ergo propter hoc. The Review of Metaphysics 30(4): 569-593.

Woods, J., and D. Walton. 1982. Argument: The logic of the fallacies. Toronto: McGraw-Hill Ryerson.

Woods, J., and D. Walton. 1989. Fallacies. Selected papers 1972-1982. Berlin-Dordrecht-Providence: de Gruyter/Foris.

Woods, J. 2004. The death of argument. Fallacies in agent based reasoning. Dordrecht: Kluwer.

Woods, J. 2013. Errors of reasoning. Naturalizing the logic of inference. London: College Publications. Yap, A. 2012. Ad hominem fallacies, bias, and testimony. Argumentation 27(2): 97-109.

Zarefky, D. 2008. Strategic maneuvering in political argumentation. Argumentation 22(3): 317-330. 